\title{
Papers
}

\section{Cost effectiveness analysis of intravenous ketorolac and morphine for treating pain after limb injury: double blind randomised controlled trial}

\author{
Timothy H Rainer, Philip Jacobs, Y C Ng, N K Cheung, Michael Tam, Peggo K W Lam, \\ Robert Wong, Robert A Cocks
}

\begin{abstract}
Objectives To investigate the cost effectiveness of intravenous ketorolac compared with intravenous morphine in relieving pain after blunt limb injury in an accident and emergency department.

Design Double blind, randomised, controlled study and cost consequences analysis.

Setting Emergency department of a university hospital in the New Territories of Hong Kong. Participants 148 adult patients with painful isolated limb injuries (limb injuries without other injuries).

Main outcome measures Primary outcome measure was a cost consequences analysis comparing the use of ketorolac with morphine; secondary outcome measures were pain relief at rest and with limb movement, adverse events, patients' satisfaction, and time spent in the emergency department.

Results No difference was found in the median time taken to achieve pain relief at rest between the group receiving ketorolac and the group receiving morphine, but with movement the median reduction in pain score in the ketorolac group was 1.09 per hour (95\% confidence interval 1.05 to 2.02) compared with 0.87 (0.84 to 1.06) in the morphine group $(\mathrm{P}=0.003)$. The odds of experiencing adverse events was 144.2 (41.5 to 501.6) times more likely with morphine than with ketorolac. The median time from the initial delivery of analgesia to the participant leaving the department was 20 (4.0 to 39.0) minutes shorter in the ketorolac group than in the morphine group $(\mathrm{P}=0.02)$. The mean cost per person was \$HK44 (£4; \$5.6) in the ketorolac group and \$HK229 in the morphine group $(\mathrm{P}<0.0001)$. The median score for patients' satisfaction was 6.0 for ketorolac and 5.0 for morphine $(\mathrm{P}<0.0001)$.

Conclusion Intravenous ketorolac is a more cost effective analgesic than intravenous morphine in the management of isolated limb injury in an emergency department in Hong Kong, and its use may be considered as the dominant strategy.
\end{abstract}

\section{Introduction \\ Clinical problem}

Patients commonly present to accident and emergency departments with severe pain after limb injury and need early treatment with effective analgesia. The use of analgesia in emergency departments and intensive care units may be suboptimal. ${ }^{1-4}$ Some analgesics, such as morphine (the opiate morphine sulphate), have a perceived risk of dependency and therefore, although relatively cheap, are regarded as "dangerous." ${ }^{5}$ In repeated frequent doses they may cause dependency, and in single doses they are associated with serious adverse effects that need monitoring and further treatment by both nursing and medical staff. Therefore these drugs, although inexpensive to buy, may have a substantial financial impact on health resources. The impact on emergency departments has never been investigated quantitatively. Non-steroidal antiinflammatory drugs are also effective at relieving moderate to severe pain and are believed to have fewer adverse effects than opiates. ${ }^{7-10}$ In North America, the United Kingdom, other parts of Europe, and in Hong Kong ketorolac (ketorolac tromethamine) is the only non-steroidal anti-inflammatory drug currently licensed for managing pain by rapid intravenous administration. ${ }^{5} 10$

\section{Economic problem}

A retrospective evaluation of the financial impact of ketorolac in hospital inpatients showed that it was associated with reduced lengths of stay and reduced use of narcotic, antipruritic, and antiemetic drugs. ${ }^{11}$ These findings were supported by a more specific study that showed that, although ketorolac was an expensive drug, its use for postoperative lumbar spine surgery reduced hospital stay by half a day with substantial financial savings. ${ }^{12}$ Both of these studies investigated cost after admission. No studies have investigated the relative economic effect of ketorolac and morphine in emergency departments.

Although intravenous morphine titrated according to the patient's needs is a current recommended gold standard against which all strong analgesics may be evaluated and compared for efficacy and safety, ${ }^{1}$ little is known about the economic aspects of its use. The few



Department of Economics, Hong Kong Baptist

University, 224

Waterloo Road,

Kowloon Tong,

Kowloon, Hong

Kong

Y C Ng

associate professor

continued over

BMJ 2000;321:1-9 
Centre for Clinical Trials and Epidemiological Research, Flat 7B, 7 th floor, Block B, Staff Quarters, Prince of Wales Hospital, Shatin Peggo K W Lam statistician

Finance

Department, Prince of Wales Hospital,

Shatin

Robert Wong business manager

Correspondence to: T H Rainer rainer1091@ cuhk.edu.hk controlled trials comparing doses of intravenous ketorolac and intravenous morphine were all either perioperative studies or associated with cancer. ${ }^{8}{ }^{13-20}$

We performed a cost effectiveness analysis comparing intravenous ketorolac with intravenous morphine in the management of pain after blunt limb injury (non-penetrating injury to a limb) in an accident and emergency department setting. We hypothesised that, although ketorolac is about three times as expensive as morphine in Hong Kong, ketorolac would be the more cost effective option if all additional related costs were taken into account.

\section{Methods}

We conducted the study in the accident and emergency department of the Prince of Wales Hospital, Shatin, a 1400 bed university teaching hospital in the New Territories of Hong Kong. The department receives over 200000 new patients a year-of whom a fifth are admitted to hospital-and serves a population of about 1500000 . Currently, health care in the emergency department is free at the point of access, and charges are made only if the patient is admitted to a ward or referred for outpatient follow up.

We obtained ethical approval from the local institutional research ethics committee to conduct a pragmatic, prospective, randomised, controlled, double blind study comparing intravenous ketorolac with morphine in the management of pain after limb injury. We obtained informed written consent from each patient. The study started with a threefold difference in cost between ketorolac and morphine, and we sought to investigate whether the difference was negated when all associated additional costs were included in a cost effectiveness analysis.

\section{Inclusion and exclusion criteria}

All patients aged $\geqslant 16$ years presenting to the emergency department between 9 am and 5 pm, Monday to Friday, with an isolated painful limb injury (limb injury without other injury) were considered for the study. The investigators did not consider it reasonable within the study budget to hire a research nurse for 24 hour or evening surveillance. As painful injuries should be treated with analgesia before specific diagnoses are made, recruitment inevitably included some patients with a high clinical probability of a fracture but who subsequently were found to have dislocations or soft tissue injuries alone. All participants were studied on an intention to treat basis, with one exception (see results section), and in the analysis both drug groups were compared to ensure no difference in the proportion with or without fractures. Patients were excluded if they had a history of substance misuse, dementia, indigestion, peptic ulceration or gastrointestinal haemorrhage, recent anticoagulation, pregnancy, adverse reaction to morphine or ketorolac, renal or cardiac failure, hepatic problems, rectal bleeding, recent $(<24$ hours $)$ use of non-steroidal anti-inflammatory drugs, asthma, chronic obstructive airways disease, chronic pain syndromes, or previous treatment with analgesia for the same injury. They were also excluded if they had a physical, visual, or cognitive impairment, as use of the visual analogue scale would have been unreliable.

\section{Interventions and randomisation}

Patients were randomly allocated to one of the two treatment groups by using a random number table. ${ }^{21}$ Ketorolac was prepared as a $2 \mathrm{mg} / \mathrm{ml}$ solution and morphine as a $1 \mathrm{mg} / \mathrm{ml}$ solution. One group would receive intravenous ketorolac as a $10 \mathrm{mg}(5 \mathrm{ml})$ loading dose over 60 seconds followed by $5.0 \mathrm{mg}(2.5 \mathrm{ml})$ every 5 minutes up to 20 minutes (maximum $30 \mathrm{mg}$ ) as required. The other group would receive intravenous morphine as a $5 \mathrm{mg}(5 \mathrm{ml})$ loading dose over 60 seconds followed by $2.5 \mathrm{mg}(2.5 \mathrm{ml})$ every 5 minutes up to 20 minutes (maximum $15 \mathrm{mg}$ ) as required. These doses were chosen partly as a result of published reports and partly as a result of the findings from the pilot study $(\mathrm{n}=40))^{2-4} .^{7-9}$ Also, the British National Formulary recommends that ketorolac should not be administered in an initial bolus of more than $30 \mathrm{mg}$ and that this should not be repeated until a further six hours has elapsed. ${ }^{5}$ Doctors at the Prince of Wales Hospital in Shatin are reluctant to administer more than $15 \mathrm{mg}$ of morphine as an initial slow bolus, so the selected doses were reasonable and practical.

A nurse with clinical responsibilities opened a precoded envelope with details of the drug and randomisation number. Either morphine or ketorolac was prepared in the emergency department according to normal practice except that the syringe was labelled with a coded number rather than the drug name. This nurse was not involved in the administration of analgesia, the assessment of the participant, or the treatment of adverse effects. The code was to be broken only if a doctor or other nurse with clinical duties was concerned about severe adverse effects. Both the research nurse, with non-clinical duties, and the participant were blinded to the treatment. The aim was to achieve total pain relief at rest-that is, a pain score of 0 -provided that the maximum dose was not exceeded and there were no adverse effects.

\section{Clinical measurements and data collection}

A 10 inch $(254 \mathrm{~mm})$, numbered (0-10), horizontal, visual analogue pain score was used for baseline measurements and at subsequent time intervals after the first injection. ${ }^{22} \mathrm{~A}$ large scale (inches rather than centimetres) was used because disability from poor vision is particularly high in Hong Kong. Routine observations, pain scores, and adverse effects were recorded every five minutes for the first 30 minutes after drug administration, at 30 minute intervals for the subsequent one and a half hours, and once more at six hours. Participants were aware of their previous scores at all stages of recording. The type, number, duration, and severity (based on the Morrow index where appropri$a^{23}$ ) of adverse effects were documented. The physician on duty was free to give extra or alternative doses of analgesia if clinically required, and this was documented. Data were analysed with SAS Statview for Windows, version 5.0 (Abacus Concepts, SAS Institute, Cary, NC, USA).

\section{Clinical and perception outcomes}

The primary clinical outcomes were pain relief measured as changes in the pain score, and adverse effects. Pain relief is presented as odds ratios of reaching $50 \%, 75 \%$, and $100 \%$ reduction in pain score (both at rest and with activity) and as median changes in the pain score estimated with the Kaplan-Meier 
Table 1 Methods and values for unit costs

\begin{tabular}{|c|c|c|}
\hline Resource item & Method used to measure quantity of resource & $\begin{array}{l}\text { Method used to measure price of resource } \\
\text { (unit cost of resource, \$HK) }\end{array}$ \\
\hline Pharmacy & $\begin{array}{l}\text { Estimated time (minutes) required by pharmacist or dispenser } \\
\text { to process a unit of prescribed drug: ketorolac (dispenser) } \\
0.34 \text {; morphine (pharmacist) } 0.30 \text { and (dispenser) } 0.23 \text {; other } \\
\text { non-opioids (dispenser) } 0.34 \text {; other opioids (pharmacist) } 0.30 \\
\text { and (dispenser) } 0.34\end{array}$ & $\begin{array}{l}\text { Pharmacist salary per hour, 552.00; dispenser salary per } \\
\text { hour, } 180.00\end{array}$ \\
\hline $\begin{array}{l}\text { Nursing officer in emergency } \\
\text { department }\end{array}$ & $\begin{array}{l}\text { Measured time (minutes) by research nurse for nurses to } \\
\text { check and prepare blinded formulation of drug: morphine, } \\
10.20 \text {; ketorolac, } 7.60\end{array}$ & $\begin{array}{l}\text { Average nursing officer salary per hour from hospital } \\
\text { finance records, } 354.00\end{array}$ \\
\hline $\begin{array}{l}\text { Registered nurse in emergency } \\
\text { department }\end{array}$ & $\begin{array}{l}\text { Time estimated by nurse manager for nurse to deliver drugs } \\
\text { in every day setting: morphine, } 2.00 \text {; ketorolac, } 1.00 \text {. } \\
\text { Measured time (minutes) by research nurse for nurses to } \\
\text { manage adverse drug effects from: morphine, } 4.40 \text {; ketorolac, } \\
7.50\end{array}$ & $\begin{array}{l}\text { Average registered nurse salary per hour from hospital } \\
\text { finance records, } 222.00\end{array}$ \\
\hline Emergency room physician & $\begin{array}{l}\text { Measured time (minutes) by research nurse for nurses to } \\
\text { manage adverse drug effects from: morphine, } 1.69 \text {; ketorolac, } \\
1.90\end{array}$ & $\begin{array}{l}\text { Average emergency room physician salary per hour from } \\
\text { hospital finance records, } 942.00\end{array}$ \\
\hline Inpatient ward costs & No of bed days in observation or hospital ward & $\begin{array}{l}\text { Average total daily ward costs from participating hospital, } \\
3650.00\end{array}$ \\
\hline Reattendance costs & Emergency department attendance costs & Average cost per patient per minute, 615.00 \\
\hline
\end{tabular}

product limit method. "Activity," for the purpose of this study, involved the research nurse gently moving the injured limb to assess pain. The same nurse performed all movements in a standardised manner. Adverse events were assessed for number, duration, and severity (where applicable). The perception outcome measures were participants' satisfaction with pain relief and their satisfaction with the care given by staff in the emergency department at the time of discharge from the department.

The end point was six hours after the administration of analgesia if the patient was discharged from the emergency department. To exclude any late effects, however, discharged participants were encouraged to return to the department if they had any adverse events, and computerised records were scanned for returns for up to four weeks after the initial attendance. Four weeks was an arbitrary period, after which any related effects were extremely unlikely. For the patients admitted to hospital, the end point was set at hospital discharge.

\section{Cost measurements and data collection}

Costs were calculated according to activities, which included the preparation and administration of analgesics and other drugs, care relating to adverse events, and admission to hospital. We obtained estimates for the time required to use each resource in each activity (table 1) and the unit costs for each of these resources. Drugs were costed separately according to dose, and cost estimates were made for the actual treatment time for adverse events.

\section{Cost effectiveness analysis}

The primary efficiency measure was a cost consequences analysis ${ }^{24}$-that is, a comparison of costs with several different outcomes. Qualitative, rather than quantitative, descriptions were made in comparing outcomes and efficiency measures. ${ }^{25}$ The sensitivity analysis of cost measures was conducted with regard to observational periods. For the patients who were discharged from the emergency department we relaxed the assumption that all possible events could be observed within the six hour study period. The true end point, however, may be six hours after the first injection, in which case the previous defined end point would not capture all of the information for the cost effectiveness analysis, especially in those discharged from the emergency department within one to two hours (for whom we assumed that any pain score after the first two hours would be the same for both groups of participants). With the extra four hours of treatment we recalculated the incremental cost effectiveness as stated above.

\section{Statistical analysis}

Data were analysed on an intention to treat basis, and we used two tailed tests in all statistical analyses. As pain score and time data did not conform to the Gaussian distribution, non-parametric tests were used to analyse data. ${ }^{26}$ Baseline characteristics of the two treatments were analysed using the $\chi^{2}$ test or MannWhitney $\mathrm{U}$ test. ${ }^{27}$ Time to event variables were evaluated by using the Kaplan-Meier product limit method, and the log rank test was used to compare the treatment groups. ${ }^{28} \mathrm{~A}$ regression line indicating the change in pain score over time was found, and its slope was therefore a summary measure for each patient. ${ }^{29}$ The median slope for each treatment group was compared and analysed by using the Mann-Whitney $\mathrm{U}$ test. The likelihood of achieving pain reduction was presented as hazard ratios.

\section{Results}

During the defined study period 182 patients attended the emergency department with acute, painful limb injuries, 149 of whom were allocated to receive blinded analgesia (figure). The 33 patients excluded from the study were excluded for the following reasons: patient decided not to enter the trial (18 patients), asthma or chronic obstructive airways disease (6), renal disease (3), peptic ulceration or gastrointestinal haemorrhage 


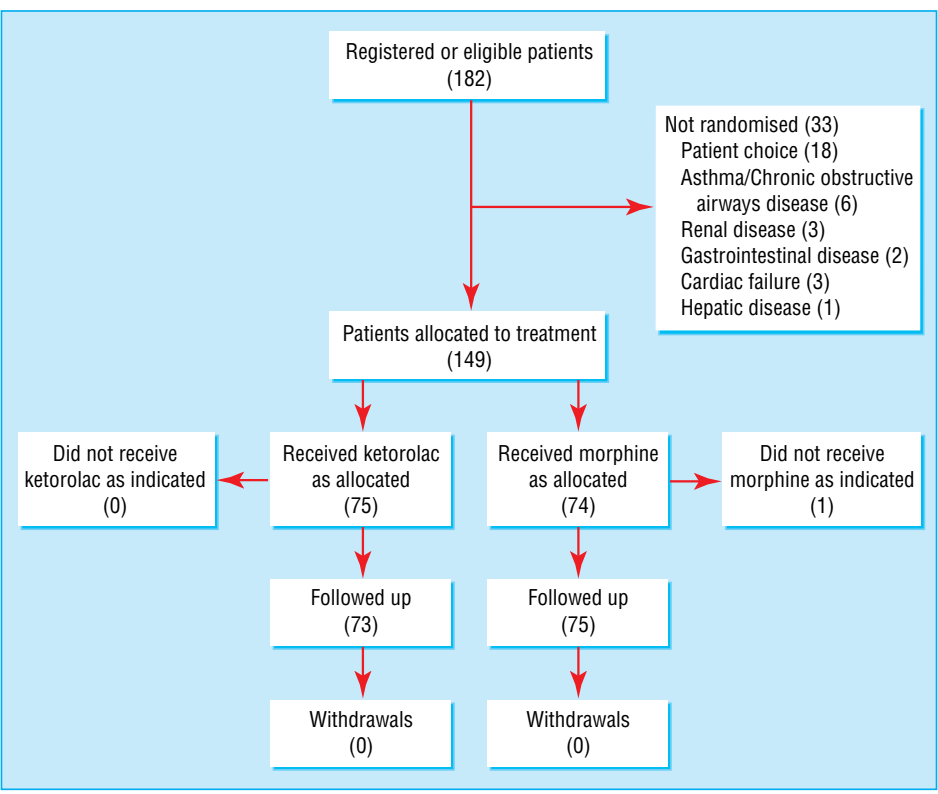

Flow chart describing progress of patients through randomised trial

(2), ischaemic heart disease (3), liver disease (1). A further patient agreed to enter the trial but was excluded by a visiting doctor who was not familiar with the study. Exceptional circumstances at the time meant that the issue was not resolved, and the patient received alternative drug treatment. The precoded envelope had been opened, but no study analgesia was adminis-

Table 2 Participants' characteristics $(n=148)$. Values are numbers (percentages $\left.{ }^{\star}\right)$ of participants unless stated otherwise

\begin{tabular}{|c|c|c|c|}
\hline Variable & $\begin{array}{l}\text { Ketorolac group } \\
\quad(n=75)\end{array}$ & $\begin{array}{l}\text { Morphine group } \\
\quad(n=73)\end{array}$ & $P$ value \\
\hline Mean (SD) age (years) & $53.9(21.7)$ & $53.2(21.8)$ & $0.85 \ddagger$ \\
\hline No $(\%)$ of men & $38(51)$ & $33(45)$ & $0.51 \S$ \\
\hline Mean (SD) body mass index $\left(\mathrm{kg} / \mathrm{m}^{2}\right)$ & $22.8(3.2)$ & $23.0(3.7)$ & $0.77 \ddagger$ \\
\hline $\begin{array}{l}\text { Mean (interquartile range) time between } \\
\text { injury and arrival at hospital (minutes) }\end{array}$ & $95(30-630)$ & $82(33-921)$ & 0.75 \\
\hline \multicolumn{4}{|l|}{ Cause of injury: } \\
\hline Motor vehicle crash & $6(8)$ & $4(5)$ & $0.58 \eta$ \\
\hline Falls & $46(61)$ & $51(70)$ & \\
\hline Crush & $20(27)$ & $14(19)$ & \\
\hline Other & $3(4)$ & $4(5)$ & \\
\hline Fractures: & $50(67)$ & $48(66)$ & $0.91 \S$ \\
\hline Clavicle, humerus, elbow & $5(7)$ & $8(11)$ & \\
\hline Radius, ulnar & $8(11)$ & $11(15)$ & \\
\hline Hand & $15(20)$ & $13(18)$ & \\
\hline Femur, patella & $14(19)$ & $12(16)$ & \\
\hline Tibia, fibula & $5(7)$ & $3(4)$ & \\
\hline Foot & $2(3)$ & $1(1)$ & \\
\hline \multicolumn{4}{|l|}{ Non-fractures: } \\
\hline Dislocation, upper limb & $2(3)$ & $1(1)$ & \\
\hline Soft tissue injury, upper limb & $10(13)$ & $10(14)$ & \\
\hline Soft tissue injury, lower limb & $14(19)$ & $14(19)$ & \\
\hline \multicolumn{4}{|l|}{ Initial mean (SD) pain score: } \\
\hline At rest & $3.8(1.1)$ & $3.9(1.1)$ & $0.65 \ddagger$ \\
\hline With activity & $8.1(1.2)$ & $8.1(1.2)$ & $0.85 \ddagger$ \\
\hline Referred for orthopaedic assessment & $41(55)$ & $36(49)$ & $0.52 \S$ \\
\hline Admitted to hospital $†$ & $38(51)$ & $29(40)$ & $0.18 \S$ \\
\hline Admitted with adverse effects & 0 & $3(4)$ & \\
\hline
\end{tabular}

*Percentages may not sum to 100 because of rounding.

†Patients admitted to hospital (to orthopaedic or emergency observation ward).

$\ddagger t$ test for unpaired means comparison.

$\S \chi^{2}$ test.

IFisher's exact test. tered. This patient was therefore excluded from the analysis because he received no study analgesia. In another case, the code was broken by an attending physician because the participant (in the morphine group) showed signs of severe drowsiness. All data were collected and the participant was included in the analysis.

\section{Baseline characteristics and clinical outcomes}

Baseline characteristics of the 148 participants in the two groups were similar (table 2). Seventy seven patients were admitted to hospital-71 to an orthopaedic ward for orthopaedic reasons and not because of adverse events after analgesia and 6 to the emergency ward. One participant (from the ketorolac group) was admitted for four days not because of adverse events after analgesia but because of poor social circumstances and immobility. Five participants were admitted from the morphine group (median stay 1 day) - two because of poor social circumstances and mobility and three because of adverse events after analgesia (dizziness, drowsiness, and vomiting).

According to the doses and methods used in this study, the odds of achieving $50 \%, 75 \%$, and $100 \%$ pain relief at rest favoured morphine, although these results were not statistically significant $(\mathrm{P}>0.05)$ (table 3$)$. With activity, the odds of achieving $50 \%$ and $75 \%$ pain reduction favoured ketorolac, although only the result for $75 \%$ pain reduction was statistically significant $(\mathrm{P}<0.05)$ (table 3). The median rate of a decrease in pain score was greater with ketorolac than with morphine (table 4). Ten minutes after the start of analgesia there was a $20 \%$ reduction in pain score for ketorolac and 32\% for morphine at rest and a $27 \%$ reduction in pain score for both ketorolac and morphine with activity (data not shown).

Participants were 16 times more likely to develop adverse effects with morphine than with ketorolac (table 5), with an odds ratio of 144.2 (95\% confidence interval 41.5 to 501.6; $\mathrm{P}<0.0001)$. The commonest adverse effects are shown in table 5 , but in addition, there were reports of sweating ( 5 participants), rashes (3), abdominal pain (3), breathlessness (2), and dry mouth (1) in morphine group and of dry mouth (1) in the ketorolac group. No participants reported headache, wheeze, chest tightness, indigestion, or gastrointestinal haemorrhage. Morrow index scores for morphine and ketorolac were 0.37 (0.23 to 0.50$)$ and $0.004 \quad(0.001$ to 0.01$)$ respectively for dizziness $(\mathrm{P}<0.001) ; 0.56$ (0.30 to 0.83$)$ and 0 respectively for nausea $(\mathrm{P}<0.001)$; and $0.43(0.14$ to 0.71$)$ and 0 respectively for vomiting $(\mathrm{P}<0.001)$.

No difference was found between the two drugs for time between injury and arrival at the emergency department (table 2) or for time between arrival at the emergency department and prescription of analgesia, preparation of analgesia, or time taken for radiography (table 6). Participants waited longer (between prescription and administration of initial bolus) to receive morphine than ketorolac $(\mathrm{P}=0.0002)$ and therefore spent longer in the emergency department, although total time spent in the emergency department was not statistically significant $(\mathrm{P}=0.11)$. The total time that nurses and doctors spent managing adverse effects was also longer for the morphine group than for the ketorolac group (table 7). 
For morphine, the dose administered divided by body mass index (weight $(\mathrm{kg}) /\left(\right.$ height $\left.(\mathrm{m})^{2}\right)$ ) correlated with time to complete pain relief at rest (Spearman's rank correlation $\left.r_{\mathrm{s}}=0.552, \mathrm{P}<0.0001\right)$, but little effect was seen with ketorolac $\left(r_{s}=0.250, \mathrm{P}=0.03\right)$. For morphine, the dose administered divided by body mass index correlated weakly with duration of vomiting $\left(r_{s}=0.311, \mathrm{P}=0.008\right)$. Correlations between age and pain score and between age and duration of vomiting were weak $\left(r_{s}<0.400\right)$.

\section{Cost analysis}

Marginal costs were used to measure the difference in costs between the two interventions (table 7). The mean cost per person, excluding admissions, was $\$$ HK43.60 ( $£ 4 ; \$ 5.6$ ) for those in the ketorolac group and $\$$ HK228.80 for those in the morphine group $(\mathrm{P}<0.0001)$. Overall mean cost per person, including admissions unrelated to analgesia, was \$HK11 361.20 for those in the ketorolac group and $\$ H K 7279.62$ for those in the morphine group $(\mathrm{P}=0.451)$. If admission costs are excluded, much of the difference between the costs for the two groups was the result of the management of adverse effects.

\section{Cost effectiveness}

When we included admission costs we observed no significant differences in costs between the two groups. We found a significant reduction in pain with activity in the ketorolac group and significantly fewer common adverse events. Additionally, the participants in the ketorolac group showed a greater degree of satisfaction with that drug than the participants in the morphine group showed with their drug (table 8). Ketorolac administration therefore is the "dominant" strategy, with significantly better outcomes, lower costs when costs for the emergency department and pharmacy are combined, but not significantly higher overall costs.

\section{Discussion}

This study shows that, although intravenous morphine costs less than intravenous ketorolac in Hong Kong, ketorolac is a cheaper option than morphine once all additional costs incurred by the accident and emergency department and the pharmacy are taken into account. When admission costs are included, however, the difference in cost is not significant. When both drugs are administered intravenously in titrated doses according to individual patients' needs, ketorolac is at least as efficacious as morphine and may afford a small advantage when the injured limb is moved. Ketorolac had fewer adverse effects than morphine, made fewer

$\begin{aligned} & \text { Table } 3 \text { Likelihood of achieving pain reduction } \\
& \text { Hazard ratio }\end{aligned}$
\begin{tabular}{lll} 
Activity level & P valuef \\
\hline At rest: & $0.83(0.60$ to 1.15$)$ & 0.271 \\
\hline $50 \%$ reduction in pain & $0.84(0.60$ to 1.16$)$ & 0.279 \\
\hline $75 \%$ reduction in pain & $0.93(0.66$ to 1.30$)$ & 0.654 \\
\hline Complete pain relief & & 0.330 \\
\hline With activity: & $1.18(0.85$ to 1.63$)$ & 0.027 \\
\hline $50 \%$ reduction in pain & $1.49(1.05$ to 2.12$)$ & \\
\hline $75 \%$ reduction in pain
\end{tabular}

${ }^{*}>1$ means that ketorolac performed better than morphine for pain relief. tWald test.

Table 4 Summary results for median rate of decrease in pain score per hour $(95 \%$ confidence intervals)

\begin{tabular}{lccc} 
& Ketorolac $(\mathbf{n}=\mathbf{7 5})$ & Morphine $(\mathbf{n}=\mathbf{7 3})$ & P value $^{*}$ \\
\hline At rest & $11.40(9.41$ to 12.77$)$ & $10.80(10.20$ to 13.54$)$ & 0.540 \\
\hline With activity & $1.09(1.05$ to 2.02$)$ & $0.87(0.84$ to 1.06$)$ & 0.003 \\
\hline
\end{tabular}

*Mann-Whitney U test.

Table 5 Numbers (percentages) of participants with adverse events*

\begin{tabular}{lccc} 
Variable & Ketorolac group $(\mathbf{n}=\mathbf{7 5})$ & Morphine group $(\mathbf{n}=\mathbf{7 3})$ & P value† \\
\hline Totalł & $4(5)$ & $65(89)$ & $<0.0001$ \\
\hline Drowsiness & $1(1)$ & $43(59)$ & $<0.0001$ \\
\hline Sleeping & 0 & $8(11)$ & 0.0054 \\
\hline Dizziness & $2(2)$ & $55(75)$ & $<0.0001$ \\
\hline Nausea & 0 & $27(37)$ & $<0.0001$ \\
\hline Vomiting & 0 & $12(16)$ & $<0.001$ \\
\hline Phlebitis & 0 & $20(27)$ & $<0.0001$
\end{tabular}

${ }^{*}$ Some participants reported more than one adverse effect.

†Fisher's exact test.

flncludes participants with uncommon adverse effects that are noted in the text but not in the table.

demands on doctors' and nurses' management time, resulted in earlier discharge or admission to a ward, and was associated with greater satisfaction among patients. Morphine may afford a small clinical advantage, however, with better odds of relieving pain at rest than with ketorolac.

\section{Originality of study}

The study has the several original aspects. Firstly, it compares intravenous ketorolac and intravenous morphine in a nurse controlled, analgesic regimen with titrations according to the individual patients' needs. None of the many other studies that have compared parenteral ketorolac with parenteral opiates in a variety of settings ${ }^{7-10} 1^{13} 1^{15-20}$ 30-41 $^{3}$ has compared one drug with the other as in this protocol. Secondly, the two drugs were studied within the context of an emergency department. Both morphine and ketorolac have been studied separately in emergency departments in both controlled and uncontrolled studies, ${ }^{10}{ }^{30} 42$ but no study has compared one with the other in this setting.

Table 6 Median number (interquartile range) of minutes relating to participants' treatment

\begin{tabular}{|c|c|c|c|c|}
\hline Variable & Ketorolac group ( $n=75)$ & Morphine group ( $n=73$ ) & $\begin{array}{l}\text { Median difference } \\
\text { (95\% confidence } \\
\text { interval) }\end{array}$ & $P$ value* \\
\hline $\begin{array}{l}\text { Interval between arrival in emergency department } \\
\text { and doctor prescribing analgesia }\end{array}$ & $38.0(30.0$ to 54.0$)$ & $39.0(29.0$ to 53.0$)$ & $1.0(-5.0$ to 7.0$)$ & 0.72 \\
\hline Preparation for analgesia & $5.0(5.0$ to 10.0$)$ & 10.0 (5.5 to 12.5$)$ & $2.0(0$ to 5.0$)$ & 0.0002 \\
\hline Undergoing radiography & $5.0(5.0$ to 10.0$)$ & $5.0(4.0$ to 10.0$)$ & $0(-1.0$ to 0$)$ & 0.75 \\
\hline Total time spent in emergency department & 155.0 (112.0 to 198.0) & 171.0 (126.0 to 208.5) & $15.0(-4.0$ to 33.0$)$ & 0.11 \\
\hline $\begin{array}{l}\text { Interval between receiving analgesia and leaving } \\
\text { emergency department }\end{array}$ & $115.0(75.0$ to 149.0$)$ & 130.0 (95.0 to 170.0$)$ & $20.0(4.0$ to 39.0$)$ & 0.02 \\
\hline
\end{tabular}


Table 7 Analysis of all costs incurred in treating participants

\begin{tabular}{|c|c|c|c|c|c|c|c|c|}
\hline \multirow[b]{2}{*}{ Variable } & \multicolumn{4}{|c|}{ Ketorolac group ( $n=75$ ) } & \multicolumn{4}{|c|}{ Morphine group ( $n=73$ ) } \\
\hline & $\begin{array}{l}\text { Unit cost } \\
\text { (\$HK) }\end{array}$ & $\begin{array}{l}\text { No of } \\
\text { particpants } \\
\text { receiving } \\
\text { service }\end{array}$ & $\begin{array}{l}\text { Mean duration } \\
\text { of service } \\
\text { received } \\
\text { (minutes) }\end{array}$ & $\begin{array}{l}\text { Average cost per } \\
\text { person }(\$ H K)\end{array}$ & $\begin{array}{c}\text { Unit } \\
\text { cost } \\
\text { (\$HK) }\end{array}$ & $\begin{array}{l}\text { No of } \\
\text { participants } \\
\text { receiving } \\
\text { service }\end{array}$ & $\begin{array}{l}\text { Mean duration } \\
\text { of service } \\
\text { received } \\
\text { (minutes) }\end{array}$ & $\begin{array}{c}\text { Average cost per person } \\
\text { (\$HK) }\end{array}$ \\
\hline \multicolumn{9}{|l|}{ Drug costs } \\
\hline Analgesia & 7.53 & 75 & NA & 7.53 & 2.81 & 73 & NA & 2.81 \\
\hline Professional fee for analgesia & 1.02 & 75 & NA & 1.02 & 3.44 & 73 & NA & 3.44 \\
\hline \multicolumn{9}{|l|}{ Extra analgesia: } \\
\hline Dologesic 32 (per tablet) & 0.10 & 12 & NA & 0.02 & 0.10 & 19 & NA & 0.03 \\
\hline Lignocaine 1\% (per $2 \mathrm{ml}$ vial) & 0.55 & 4 & NA & 0.03 & 0.55 & 8 & NA & 0.06 \\
\hline Pethidine (per 75 mg vial) & 3.00 & 3 & NA & 0.12 & 3.00 & 1 & NA & 0.04 \\
\hline Diclofenac (per tablet) & 1.00 & 3 & NA & 0.04 & 1.00 & 1 & NA & 0.01 \\
\hline \multicolumn{9}{|l|}{ Professional fee for extra analgesia: } \\
\hline Non-opioid drug & 1.02 & 18 & NA & 0.25 & 1.02 & 28 & NA & 0.39 \\
\hline Opioid drug & 3.44 & 3 & NA & 0.14 & 3.44 & 1 & NA & 0.05 \\
\hline \multicolumn{9}{|l|}{ Drugs to treat adverse events: } \\
\hline Naloxone (per $400 \mu \mathrm{g}$ vial) & 17.8 & 0 & NA & 0 & 17.80 & 5 & NA & 1.22 \\
\hline Glyceryl trinitrate (per tablet) & 0.10 & 0 & NA & 0 & 0.10 & 1 & NA & 0.01 \\
\hline \multicolumn{9}{|l|}{ Professional fee for adverse effects of drugs: } \\
\hline Non-opioid drug & 1.02 & 0 & NA & 0 & 1.02 & 22 & NA & 0.31 \\
\hline Opioid drug & 3.44 & 0 & NA & 0 & 3.44 & 0 & NA & 0 \\
\hline \multicolumn{9}{|l|}{ Human resources costs } \\
\hline \multicolumn{9}{|l|}{ Nursing time: } \\
\hline To prepare drug & 3.70 & 75 & 7.64 & 28.27 & 3.70 & 73 & 10.16 & 37.59 \\
\hline To deliver drug & 3.70 & 75 & 1.0 & 3.70 & 5.90 & 73 & 2.0 & 11.80 \\
\hline To manage adverse effects of drugs & 3.70 & 4 & 7.26 & 1.43 & 3.70 & 65 & 4.37 & 14.40 \\
\hline Doctors' time to manage adverse effects of drugs & 15.70 & 4 & 1.25 & 1.05 & 15.70 & 65 & 1.72 & 24.04 \\
\hline Reattendance costs & 615.00 & 0 & NA & NA & 615.00 & 1 & NA & 8.45 \\
\hline Admission costs for adverse events (per day) & 3010.00 & 0 & NA & NA & 3010.00 & 3 & $1 \dagger$ & 123.70 \\
\hline Other admission costs (per day) & 3010.00 & 38 & 7.42 & 11317.60 & 3010.00 & 29 & 5.90 & 7050.82 \\
\hline \multicolumn{9}{|l|}{ Total average (SD) cost per person } \\
\hline
\end{tabular}

$£ 1=\$ H K 11$.

$\mathrm{NA}=$ not applicable.

Professional fee refers to the pharmacy costs in processing and checking the drugs.

${ }^{*}$ Mann-Whitney $\mathrm{U}$ test, $\mathrm{P}<0.0001$

†1 day.

Thirdly, a cost effectiveness analysis drew together the strands of efficacy, adverse effects, resource demands, and participants' satisfaction. Other studies have shown that ketorolac may be as efficacious as morphine and tolerated better, but none has examined the issue in a broader economic context.

\section{Study protocol versus routine practice}

This study differs from normal emergency department practice in several respects. In normal practice no delay occurs as a result of patient information and consent procedures. The delay in this study was kept to an absolute minimum, and no complaints were received from patients or relatives. Secondly, in normal practice, analgesia is not given in a blinded regimen and patients are not observed and questioned closely by a research nurse. Some degree of artificiality has to be accepted if vital data are to be recorded. As the study was randomised and double blind, however, any deviations from normal should at least be the same for both groups, leaving the effect of the two analgesics as the only difference in outcome.

\section{Strengths and shortcomings}

The strengths of the study lie in its randomised controlled design, delivery of analgesia according to individual needs, and its attempt to reflect the real world as far as reasonably possible. The economic evaluation follows recent guidelines published in the $B M J \cdot{ }^{43-45}$ Although every effort was made to blind both the research nurses and the participants to treatment, certain clinical clues-such as pinpoint pupils-might reveal the identity to discerning medical and paramedical staff. This is a shortcoming that is probably unavoidable and applies to all double blind studies comparing opiates with other drugs. In an ideal double blind regimen, treatment should not be prepared anywhere near the scene of research, so that contamination is completely impossible. In this study, nurses prepared the drugs within the department and

Table 8 Participants' satisfaction with analgesia and with emergency department management

\begin{tabular}{|c|c|c|c|c|}
\hline \multirow[b]{2}{*}{ Variable } & \multicolumn{2}{|c|}{ Median (interquartile range) } & \multirow{2}{*}{$\begin{array}{l}\text { Median difference }(95 \% \\
\text { confidence interval) }\end{array}$} & \multirow[b]{2}{*}{ P value* } \\
\hline & Ketorolac group & Morphine group & & \\
\hline Satisfaction with analgesia & $6.0(5.0-6.0)$ & $5.0(4.0-6.0)$ & $1.0(1.0-2.0)$ & $<0.0001$ \\
\hline Satisfaction with emergency department management & $6.0(5.0-7.0)$ & $6.0(5.0-6.0)$ & 0 & 0.30 \\
\hline
\end{tabular}


used normal stock. This was important if we were to monitor the "real" time taken to prepare drugs for delivery and the different grades of nurses taking part in the process. The delay in starting to administer morphine compared with ketorolac was due to the extra checking procedures necessary for administering opiates.

Although more participants were admitted to hospital in the ketorolac group, the overall greater costs were not significant. No participant was admitted to an orthopaedic ward because of adverse drug effects (admission was principally for management of the injured limb). Only three of the six participants observed in an emergency observation ward were admitted specifically for adverse effects, and all were in the morphine group. Admission costs are much greater and more variable than for analgesia and associated drugs, which may explain why, when all additional costs are included, no difference was found between the two treatments. Others have noted that non-urgent visits to emergency departments cost relatively little when compared with the cost of admission. $^{46}$

Baseline pain scores at rest were not high, and it may be argued that many of the participants did not need strong analgesia. With only minor degrees of movement, however, the average pain score rose to over 8 (out of a possible 10), showing that these participants did experience severe pain and that the administration of strong analgesia was appropriate. We could not study a placebo effect as it would have been both unethical and unjustified to deny some participants appropriate analgesia when they were in moderate to severe pain. Limb injuries are clearly painful, however, and most participants in this study had fractures confirmed by radiography. The reductions in pain score exceeded the minimum required for clinical significance. ${ }^{478}$

The primary aim of this study was to investigate costs related to the input from the emergency department to pain management, but to follow any prolonged or delayed adverse events we had to extend data collection beyond the emergency department. No attempt was made to evaluate subsequent analgesia. Principal adverse events included drowsiness, sleeping, dizziness, nausea, vomiting, and phlebitis. These events occurred in a greater proportion of participants (and with greater severity and duration) in the morphine group than in the ketorolac group. Adverse events drain nursing resources, which during busy periods would be better used elsewhere. No cases of serious adverse effects, such as gastrointestinal haemorrhage, occurred in this study, which may be partly the result of the stringent exclusion criteria. One case of a serious adverse effect in either the morphine or the ketorolac group might dramatically alter the relative cost of each drug. It is difficult to assess the relative cost of rare drug reactions in any study, but provided that care is taken to exclude high risk subjects, then serious adverse effects should be few. In a post-marketing surveillance study the risk of gastrointestinal complications after intravenous ketorolac was low especially when treatment was limited to less than five days. ${ }^{49}$ Few patients were excluded from our study on the basis of an existing medical illness, showing that this study has relevance to most adults presenting to emergency departments with isolated painful limb injury.

Routinely administering an antiemetic with an opiate such as morphine might reduce adverse events with overall lower costs, and if lower doses of morphine were administered fewer adverse events might have occurred. However, the correlation between morphine dose and pain relief suggests that lower doses would have resulted in reduced analgesic effect. The poor correlation between morphine dose and vomiting also suggest that small reductions in the dose would not have influenced the duration of this adverse effect. It is surprising that there was no difference in age between the two groups. Any relation between perception of pain and age in this study was weak. Also, a relation between age and adverse events was not evident. The study protocol was designed such that reduced doses of analgesia would be given if adverse events arose, which may account for the poor correlation with age.

The time spent ordering, delivering, and controlling stock has not been taken into account as many other drugs are involved in those processes, and the contribution of ketorolac and morphine could not be evaluated separately. Average salaries of nurses and doctors have been used as a cost reference, but in real life more junior or senior staff may have a greater actual involvement.

Participants were studied between 9 am and 5 pm and only on weekdays. It is therefore unclear whether out of hours ratios of staff to patients, case mix, and demand would affect the results. Emergency departments function on a priority system, whereby the efficiency of processing an individual patient depends on the number of patients with higher priority in the department at a given time and the available resources. This study did not address the difficult and complex relations between the individual patient and the total demand on the rest of the department at the time that patient attended. If it is assumed that staff are always doing something useful while at work, then minutes of freedom from managing one patient means that other duties may be attended to, and this has an impact on cost effectiveness.

It is difficult to know how far these results may be applied to settings outside Hong Kong. If one assumes, however, that the difference in costs between ketorolac and morphine is 7.5-fold rather than 2.5-fold, that doctors and nurses salaries are a third of those in Hong Kong, and that all other variables are the same, then ketorolac and morphine are equally cost effective (data not shown).

\section{Implementing results}

The management of pain remains one of the great challenges for emergency departments worldwide, and so policies on rapid, cost effective, and safe analgesia are essential for good patient care and patient satisfaction. High demand and prolonged waiting times also provide a drain on emergency departments' resources, and so any intervention that reduces the time that patients spend in the department is also important. This study showed that intravenous ketorolac is more cost effective than intravenous morphine in the management of acute pain after blunt limb injury in an emergency department. Doctors may be more confident about using an effective analgesic with no 


\section{What is already known on this topic}

Intravenous morphine sulphate is generally as effective as intravenous ketorolac tromethamine for surgical and cancer related pain

Morphine may cause more adverse events than ketorolac

No cost effectiveness analyses have compared the use of intravenous ketorolac and morphine titrated according to patient needs and none has evaluated such use in emergency departments

\section{What this study adds}

For limb injury in an emergency department ketorolac is as effective as morphine for pain at rest; for pain with movement, however, ketorolac may be marginally better than morphine

Ketorolac produced fewer, less severe, and shorter adverse events than morphine

Participants receiving ketorolac left the emergency department sooner than those receiving morphine

Ketorolac is a more cost effective analgesic than morphine in this setting and is associated with greater patient satisfaction

risk of dependence, fewer adverse effects, reduced arrival to discharge times in their departments, and reduced costs. These results are relevant to emergency departments in Hong Kong and are likely to be applicable to other systems that are organised along similar lines. Differences in staff salaries and other costs, however, may limit the application of our findings to some environments.

Contributors: THR had the idea for the study, obtained approval, and has overseen the entire planning, execution, and analysis of the study, and the preparation of the manuscript. $\mathrm{He}$ is guarantor of the paper. $\mathrm{PJ}$ and $\mathrm{YCN}$ participated in planning a detailed economic analysis. NKC, MT, and RAC participated in the planning, execution, and analysis. PKWL and THR prepared the statistical analysis. RW was involved in planning and costing analysis. THR wrote the first draft of the paper, and all authors have contributed to the final version.

Funding: This study was supported by the direct grants scheme of the Chinese University of Hong Kong (project code 2040668) and the Health Services Research Committee of Hong Kong (project code 921020).

Competing interests: None declared.

1 Yealy DM. Ketorolac in the treatment of acute pain: The pendulum swings. Ann Emerg Med 1992;21:985-6.

2 Goodacre SW, Roden RK. A protocol to improve analgesia use in the accident and emergency department. J Accid Emerg Med 1997;13:177-9.

3 Whipple JK, Lewis KS, Quebbeman EJ, Wolff M, Gottlieb MS, Medicus-Bringa M, et al. Analysis of pain management in critically ill patients. Pharmacotherapy 1995;15:592-9.

4 Jantos TJ, Paris PM, Menegazzi JJ, Yealy DM. Analgesic practice for acute orthopaedic trauma pain in Costa Rican emergency departments. Ann Emerg Med 1996;28:145-50.

5 British Medical Association, Royal Pharmaceutical Society of Great Britain. British national formulary. London: BMA, RPS, 1997. (No 32.)

6 Benedetti C, Butler SH. Systemic analgesics. In: Bonica JJ, ed. The management of pain. 2nd ed. Philadelphia: Lee and Febiger, 1990;1640-75.

7 Gillis JC, Brogden RN. Ketorolac. An appraisal of its pharmacodynamic and pharmacokinetic properties and therapeutic use in pain management. Drugs 1997;53:139-88.

8 Brown CR, Moodie JE, Wild VM, Bynum LJ. Comparison of intravenous ketorolac tromethamine and morphine sulphate in the treatment of postoperative pain. Pharmacotherapy 1990;10:116-21S.
9 Purday JP, Reichert CC, Merrick PM. Comparative effects of three doses of intravenous ketorolac or morphine on emesis and analgesia fo restorative dental surgery in children. Can J Anaesth 1996;43:221-5.

10 Cordell WH, Wright SW, Wolfson AB, Timerding BL, Maneatis TJ, Lewis RH, Bynum L, Nelson DR. Comparison of intravenous ketorolac, meperidine, and both (balanced analgesia) for renal colic. Ann Emerg Med 1996;28:151-8.

11 Burke JP, Pestotnik SL, Classen DC, Lloyd JF. Evaluation of the financial impact of ketorolac tromethamine therapy in hospitalized patients. Clin Ther 1996;18:197-211.

12 Turner DM, Warson JS, Wirt TC, Scalley RD, Cochran RS, Miller KJ. The use of ketorolac in lumbar spine surgery: a cost-benefit analysis. J Spinal Disord 1995;8:206-12.

13 Watcha MF, Jones MB, Lagueruela RG, Schweiger C, White PF. Comparison of ketorolac and morphine as adjuvants during pediatric surgery. Anaesthesiology 1992;76:368-72.

14 Maunuksela EL, Kokki H, Bullingham RE. Comparison of intravenous ketorolac with morphine for post-operative pain in children. Clin Pharmacol Ther 1992:52:436-43.

15 Etches RC, Warriner CB, Badner N, Buckley DN, Beattie WS, Chan VW, et al. Continuous intravenous administration of ketorolac reduces pain and morphine consumption after total hip or knee arthroplasty. Anesth Analg 1995;81:1175-80.

16 Bosek V, Miguel R. Comparison of morphine and ketorolac for intravenous patient-controlled analgesia in postoperative cancer patients. Clin J Pain 1994;10:314-8.

17 Peirce RJ, Fragen RJ, Pemberton DM. Intravenous ketorolac tromethamine versus morphine sulfate in the treatment of immediate postoperative pain. Pharmacotherapy 1990;10:111-5S

18 Gunter JB, Varughese AM, Harrington, Wittkugel EP, Patankar SS, Matar MM, et al. Recovery and complications after tonsillectomy in children: a comparison of ketorolac and morphine. Anesth Analg 1995;81:1136-41.

19 Cepeda MS, Vargas L, Ortegon G, Sanchez MA, Carr DB. Comparative analgesic efficacy of patient-controlled analgesia with ketorolac versus morphine after elective intraabdominal operations. Anesth Analg 1995;80:1150-3.

20 Munro HM, Riegger LQ, Reynolds PI, Wilton NC, Lewis IH. Comparison of the analgesic and emetic properties of ketorolac and morphine for paediatric outpatient strabismus surgery. Br J Anaes 1994;72:624-8.

21 Kirkwood BR. Essentials of medical statistics. Oxford: Blackwell Science, 1988:167-72.

22 Huskisson EC. Measurement of pain. Lancet 1974;2:1127-31

23 Morrow GR, Lindke J, Black P. Measurement of quality of life in patients: psychometric analyses of the functional living index-cancer (FLIC). Qual Life Res 1992;5:287-96.

24 Drummond MF, O'Brien B, Stoddart GL, Torrance GW. Methods for the economic evaluation health care programmes. Oxford: Oxford Medical, 1997.

25 Bakker C, Hidding A, Linden S. Cost-Effectiveness of group physical therapy compared to individualized therapy for ankylosing spondylitis: a randomized controlled trial. J Rheum 1994;21:264-8.

26 Gaddis GM, Salomone JA, Watson WA. Most linear analogue pain data should be analyzed by nonparametric statistical techniques. Ann Emerg Med 1992;21:629.

27 Bland M. An introduction to medical statistics. 2nd ed. Oxford: Oxford Publications, 1995

28 Marubini E, Valsecchi MG. Analysing survival data from clinical trials and observational studies. New York: John Wiley, 1995.

29 Matthews JNS, Altman DG, Campbell MJ, Royston P. Analysis of serial measurements in medical research. BMJ 1990;300:230-5.

30 Koenig KL, Hodgson L, Kozak R, Jordan K, Sexton TR, Leiken AM. Ketorolac vs meperidine for the management of pain in the emergency department. Acad Emerg Med 1994;1:544-9.

31 Fricke JR Jr, Angelocci D, Fox K, McHugh D, Bynum L, Yee JP. Comparison of the efficacy and safety of ketorolac and meperidine in the relief of dental pain. J Clin Pharmacol 1992;32:376-84.

32 Folsland B, Skulberg A, Halvorsen P, Helgesen KG. Placebo-controlled comparison of single intramuscular doses of ketorolac tromethamine and pethidine for post-operative analgesia. J Int Med Res 1990;18:305-14.

33 O'Hara DA, Fragen RJ, Kinzer M, Pemberton D. Ketorolac tromethamine as compared with morphine sulphate for the treatment of postoperative pain. Clin Pharmacol Ther 1987;41:556-61.

34 Stanski DR, Cherry C, Bradley R, Sarnquist FH, Yee JP. Efficacy and safety of single doses of intramuscular ketorolac tromethamine compared with meperidine for postoperative pain. Pharmacotherapy 1990;10:40-4S.

35 Stouten EM, Armbuster S, Houmes RJ, Prakash O, Erdmann W, Lachmann B. Comparison of ketorolac and morphine for postoperative pain after major surgery. Acta Anaesthesiol Scand 1992;36:716-21.

36 Parke TJ, Millett S, Old S, Goodwin AP, Rice AS. Ketorolac for early postoperative analgesia. J Clin Anesth 1995;7:465-9.

37 Rice AS, Whitehead EM, O'Sullivan G, Lloyd J, Bullingham RE. Speed of onset of analgesic effect of intravenous ketorolac compared to morphine and placebo. Eur J Anaesthesiol 1995;12:313-7.

38 Severino FB, Sinatra RS, Paige D, Silverman DG. Intravenous ketorolac as an adjunct to patient-controlled analgesia (PCA) for the management of postgynaecological surgical pain. J Clin Anesth 1994;6:23-7.

39 Beattie WS, Warriner CB, Ethches R, Badner NH, Parsons D, Buckley N, Chan V, Girard M. The addition of continuous intravenous infusion of ketorolac to a patient-controlled analgesic morphine regime reduced postoperative myocardial ischemia in patients undergoing elective total hip or knee arthroplasty. Anesth Analg 1997;84:715-22.

40 Vetter TR, Heiner EJ. Intravenous ketorolac as an adjuvant to pediatric-controlled analgesia with morphine. J Clin Anesth 1994;6:110-3.

1 Gin T, Kan AF, Lam KK, O'Meara ME. Analgesia after cesarean section with intramuscular ketorolac or pethidine. Anaes Intens Care 1993;21:420-3. 
42 Bartfield JM, Kern AM, Raccio-Robak N, Snyder HS, Baevsky RH. Ketorolac tromethamine use in a university-based emergency department. Acad Emerg Med 1994;1:532-8.

43 Byford S, Raftery J. Perspectives in economic evaluation. BMJ 1998;316:1529.

44 Palmer S, Byford S, Raftery J. Types of economic evaluation. BMJ 1999;318:1349.

45 Torgerson D, Raftery J. Main outcomes in economic evaluation. BMJ 1999;318:1413.

46 Williams RM. The costs of visits to emergency departments. N Engl J Med 1996;334:642-6.
47 Todd KH, Funk JP. The minimum clinically important difference in physician-assigned visual analog pain score. Acad Emerg Med 1996;3:142-6.

48 Todd KH, Funk KG, Funk JP, Bonacci R. Clinical significance of reported changes in pain severity. Ann Emerg Med 1996;27:485-9.

49 Strom BL, Berlin JA, Kinman JL, Spitz PW, Hennessy S, Feldman H, et al. Parenteral ketorolac and risk of gastrointestinal and operative site bleeding. A postmarketing surveillance study. JAMA 1996;275:376-82.

(Accepted 8 August 2000) 